\title{
Agar-immobilized basil-lactic acid bacteria bioproducts as goat milk taste-masking agents and natural preservatives for the production of unripened goat cheese
}

\author{
Elena Bartkiene, ${ }^{1}$ Ruta Laurikietyte, Vita Lele, Paulina Zavistanaviciute, Erika Mozuriene, \\ and Aldona Baltusnikiene \\ Department of Food Safety and Quality, Lithuanian University of Health Sciences, Tilzes St. 18, LT-47181 Kaunas, Lithuania
}

\begin{abstract}
Goat milk cheeses have become popular recently; however, many consumers do not choose these products because they have specific sensory properties that are not acceptable to all consumers and the shelf life of the cheese is short. The concept of this work was to increase overall acceptability and shelf life of unripened goat milk cheese by using Ocimum basilicum and lactic acid bacteria (Lactobacillus plantarum LUHS135, Lactobacillus paracasei LUHS244, Pediococcus pentosaceus LUHS100, Pediococcus acidilactici LUHS29, and Lactobacillus brevis LUHS140) bioproducts (basil-LAB) immobilized in agar. A basil-LAB bioproduct could be a promising multifunctional ingredient for cheese manufacturing because it has a low $\mathrm{pH}$, high LAB count, and high total phenolic compound content (after fermentation $\mathrm{pH}$ decreased by $25.4 \%$, LAB count averaged $7.2 \log _{10} \mathrm{cfu} / \mathrm{g}$, and total phenolic compound content increased by $30.9 \%$ ). Use of different LAB in the preparation of basil-LAB bioproducts had a significant influence on cheese $\mathrm{pH}$ and hardness, and compared with cheese samples prepared with nonfermented basil, cheese samples prepared with basil-LAB bioproducts had, on average, higher $\mathrm{pH}$ (by 2.6\%) and lower hardness (by 36.0\%), similar to the control cheese (without basil). Overall acceptability of cheese was significantly influenced by the basil-LAB bioproduct immobilization process; in all cases, cheese samples prepared with fermented and immobilized basil-LAB bioproduct had better acceptability (5 points). After $120 \mathrm{~h}$ of storage, cheese samples prepared with basil-LAB bioproducts fermented with LUHS135, LUHS244 and LUHS140, no enterobacteria were found, and we detected strong negative and moderate negative correlations, respectively, of LAB count with enterobacteria count and yeast/mold
\end{abstract}

Received March 19, 2018.

Accepted August 16, 2018.

${ }^{1}$ Corresponding author: elena.bartkiene@lsmuni.lt count $(\mathrm{r}=-0.7939$ and $\mathrm{r}=-0.4495$, respectively). Finally, immobilization increased LAB viability in fresh goat milk cheese, which led to a reduction in enterobacteria and mold/yeast contamination during storage and an increase in overall acceptability compared with nonimmobilized basil-LAB. Therefore, basil-LAB bioproducts fermented with LUHS135, LUHS244, and LUHS140 strains can be recommended for preparing fresh goat milk cheese with extended shelf life and high acceptability.

Key words: unripened curd cheese, goat milk, lactic acid bacteria, Ocimum basilicum L., immobilization

\section{INTRODUCTION}

In recent years, goat milk and its products have received much attention as functional foods for maintaining the nourishment and health of the young and elderly, especially those who have an allergy to cow milk (Yangilar, 2013). Goat milk differs from cow and human milk in having better digestibility, buffer capacity, alkalinity, and therapeutic values, as well as having fat with better physical properties (i.e., surface tension, viscosity, and specific gravity) than cow milk (Park et al., 2007). Goat milk is commonly used for the production of fresh unripened cheese (Janštová et al., 2010), a versatile nutrient-dense dairy product susceptible to physical, chemical, microbiological, and biochemical spoilage that can decrease its shelf life and cause serious risks to consumers' health (Jalilzadeh et al., 2015; Gouvea et al., 2017; Khorshidian et al., 2017). Changes that limit shelf life include creaming of fat, gelation of protein solutions, syneresis of curds and crystallization of minerals, nonenzymatic browning and oxidation of fat, growth of microorganisms, enzymatic degradation, ripening of cheese, and fermentation (Kilcast and Subramaniam, 2011). Increasing demand from consumers to use food products without preservatives or with natural preservatives has compelled food industries to use preservatives of herbal and microbial origin instead of artificial preservatives (Gouvea et al., 2017; Khorshid- 
ian et al., 2017). Basil (Ocimum basilicum L.) belongs to the Lamiaceae family of herbs, which, in addition to being used as a spice, is medicinally known as a powerful antibacterial, antimutagenic, and chemopreventive agent (Stanojevic et al., 2017). These plants are considered to be a rich source of essential oils that have biological activity and use in different areas of human activity (Avetisyan et al., 2017). The essential oils from various basil cultivars can contain alcohols (linalool), oxides (1,8-cineole), phenols (eugenol, methyl eugenol, methyl isoeugenol, thymol), esters (methyl cinnamate), aldehydes (citral) and camphor; 1,8-cineole, methyl cinnamate, methyl chavicol, and linalool are the constituents responsible for the distinct aroma of basil plants (Klimankova et al., 2008). Numerous papers have been published on the antimicrobial and antioxidant properties of basil essential oils and their constituents (Soković et al., 2007; Liu et al., 2012; Zabka et al., 2014; Huang et al., 2015).

To increase the preparation of goat milk products and consumer demand, it is necessary to increase their safety, improve their flavor, and to increase their functional value; lactic acid bacteria (LAB) can be used to achieve this (de Souza and Silva Dias, 2017) as they are regarded as health-friendly for consumers (Bulajic et al., 2017). Lactic acid bacteria are the dominant indigenous microorganisms of raw milk cheese, producing pathogen-inhibiting substances and leading to the manufacture of cheese with desirable microbiological qualities (Tamang et al., 2016). Our previous research confirmed that the positive effect of LAB on raw milk fresh cheese can be enhanced by combining LAB and savory plant bioproducts (Mozuriene et al., 2016). Plant bioproducts significantly reduced the counts of enterobacteria, yeast, fungi, and spores of mesophilic bacteria in cheese samples and increased the amount of volatile compounds in cheese. Bioproducts derived from a combination of LAB and savory plants increased the acceptability and shelf life of cow milk curd cheese, and therefore can be recommended for the production of better quality curd cheese (Mozuriene et al., 2016).

The concept of this work was to increase overall acceptability and shelf life of unripened goat milk cheese by using Ocimum basilicum-LAB bioproducts (basilLAB) immobilized in agar.

\section{MATERIALS AND METHODS}

\section{Plant Material and Microorganisms Used for Fermentation}

Fresh $O$. basilicum was obtained from a local market. Before the experiment, plants were washed under running water and homogenized by using a Bosch MSM67170 homogenizer (Robert Bosch GmbH, Stuttgart, Germany) to obtain a puree consistency.

Lactobacillus plantarum LUHS135, Lactobacillus paracasei LUHS244, Pediococcus pentosaceus LUHS100, Pediococcus acidilactici LUHS29, and Lactobacillus brevis LUHS140 strains were obtained from the culture collection of the Lithuanian University of Health Sciences (Kaunas, Lithuania). The LAB were cultured at $30^{\circ} \mathrm{C}$ for $24 \mathrm{~h}$ in de Man, Rogosa, and Sharpe (MRS) broth (CM0359, Oxoid Ltd., Basingstoke, UK) and used for further experiments.

\section{Preparation of Agar-Immobilized Basil-LAB Bioproducts}

The homogenized plant samples $(500 \mathrm{~mL})$ were inoculated with pure LAB cultures ( $3 \%$ by volume). A cell suspension of LAB containing about $9.4 \log _{10} \mathrm{cfu} / \mathrm{mL}$ was added to the homogenized plant sample, followed by fermentation for $24 \mathrm{~h}$ at $30 \pm 2^{\circ} \mathrm{C}$. Prepared basilLAB bioproducts were immobilized in agar. First, agar powder was soaked in water $(70.2 \mathrm{~g} / \mathrm{L})$ for $20 \mathrm{~min}$ and then melted by heating for $5 \mathrm{~min}$. Basil-LAB bioproducts were incorporated into the agar mass (80:20, basil: agar, $\%$ by volume) at the end of the process, when the agar solution was cooled to $30 \pm 2^{\circ} \mathrm{C}$. The obtained mass was poured into molds and dried at room temperature $\left(21-23^{\circ} \mathrm{C}\right)$ for $24 \mathrm{~h}$ to a gel-like texture. The mass was divided, by cutting with a knife, into granules $3 \mathrm{~mm}$ in diameter and directly used for the analysis and preparation of unripened goat milk cheese. During this experiment, 5 basil-LAB bioproducts were prepared by using different LAB strains (L. plantarum LUHS135, L. paracasei LUHS244, P. pentosaceus LUHS100, $P$. acidilactici LUHS29, and L. brevis LUHS140). Nonfermented homogenized $O$. basilicum was tested as a control. Unripened goat milk cheese was prepared by using 5 immobilized, 5 nonimmobilized, and 1 nonfermented $O$. basilicum, and without $O$. basilicum.

\section{Preparation of Unripened Goat Milk Cheese}

Raw goat milk (normal, clean, and white; natural flavor without any foreign matter or adulteration; $\mathrm{pH}$ 6.6 , milk solids-not-fat $8.25 \%$, total microorganisms $<5$ $\times 10^{4} \mathrm{cfu} / \mathrm{mL}$, somatic cells $<7 \times 10^{5}$ cells $/ \mathrm{mL}$, protein content $3.8 \%$, fat content $4.0 \%$, total solids $13.1 \%$ ) was collected from Laurikieciu farm (Pakruojis, Lithuania). The curd cheese was made using $10 \mathrm{~L}$ of raw goat milk per treatment. Raw milk intended for unripened (fresh) cheese was pasteurized in a batch pasteurizer at 72 to $73^{\circ} \mathrm{C}$ for 15 to $20 \mathrm{~s}$. After spontaneous coagulation 
(after $24 \mathrm{~h}$ at $30 \pm 2^{\circ} \mathrm{C}$ ) of the milk, curd was gently mixed, using a spoon, with $5 \%$ basil-LAB bioproduct (by weight) and $2 \%$ salt; it was then gently cut into cubes of approximately $100 \mathrm{~g}$, drained, placed in nylon containers, and pressed (0.5-kg weight) for $12 \mathrm{~h}$ at $4^{\circ} \mathrm{C}$. Curd cheese samples for analysis were collected within $24 \mathrm{~h}$ of the manufacturing process.

\section{Analysis of Acidity Parameters of Basil-LAB Bioproducts and Curd Cheese}

The $\mathrm{pH}$ values of basil-LAB bioproducts were measured and recorded with a $\mathrm{pH}$ electrode (PP-15, Sartorius, Goettingen, Germany). A cheese slurry was prepared by blending $20 \mathrm{~g}$ of grated cheese with 12 $\mathrm{mL}$ of water; then, $20 \mathrm{~g}$ of sample was mixed with 250 $\mathrm{mL}$ of distilled water and filtered through Whatman \#1 filter paper to determine the total titratable acidity (TTA, $\mathrm{T}^{\circ}$ ), and $25 \mathrm{~mL}$ of the filtered sample was titrated with $0.1 \mathrm{~mol} / \mathrm{L} \mathrm{NaOH}$. Phenolphthalein was used as an indicator.

\section{Analysis of Total Phenolic Compound Content and Determination of Free Radical Scavenging Activity}

The total phenolic compounds (TPC) content of basil-LAB bioproducts was determined by using a spectrophotometric method, as reported by Vaher et al. (2010). The absorbance of samples was measured at $765 \mathrm{~nm}$ using a V-1100D spectrophotometer (J.P. Selecta S.A., Barcelona, Spain). The 2,2-diphenyl-1-picrylhydrazyl (DPPH) free radical scavenging activity (FRSA) of the samples was determined according to the method reported by Zhu et al. (2011).

\section{Evaluation of Color, Texture, and Overall Acceptability}

Color characteristics of basil-LAB bioproducts and curd cheese were assessed using a CIELAB system (Chromameter CR-400, Konica Minolta, Tokyo, Japan). The hardness parameter was evaluated by using a Brookfield texture analyzer (Middleborough, MA). Sensory analysis of basil-LAB bioproducts and curd cheese was carried out according to ISO method 6658 (ISO, 2017) for overall acceptability by 10 selected assessors using a 5-point hedonic scale ranging from 1 (extremely dislike) to 5 (extremely like). Ten assessors were recruited internally (Department of Food Safety and Quality, Lithuanian University of Health Sciences, Kaunas, Lithuania; ISO, 2008, 2012): 5 females and 5 males, from 35 to $45 \mathrm{yr}$ old. Individuals who were familiar with this study were excluded from the panel. The previous training of the assessors was based on descriptive analysis (Gaze et al., 2015; Janiaski et al., 2016; Torres et al., 2017). Selected assessors were nonsmokers, interested in sensory analysis, and motivated to participate.

\section{Microbiological Analysis of Basil-LAB Bioproducts and Unripened Goat Milk Cheese}

Viability of LAB was evaluated in basil-LAB bioproducts and cheese samples; LAB counts were determined on MRS agar (Liofilchem, Roseto degli Abruzzi, Teramo, Italy) using standard plate count techniques (ISO, 1998). Plates were incubated at $30^{\circ} \mathrm{C}$ for $72 \mathrm{~h}$ under anaerobic conditions (using an AnaeroGen atmosphere generation system; Oxoid).

Curd cheese analysis was performed after 24,72 , and $120 \mathrm{~h}$ of storage at $4^{\circ} \mathrm{C}$; LAB counts were determined on MRS agar (Liofilchem) using standard plate count techniques. Enterobacteria were determined on violet red bile glucose agar (VRBA, Liofilchem) after incubation at $37^{\circ} \mathrm{C}$ for $24 \mathrm{~h}$. Yeasts and fungi were determined on chloramphenicol agar (CM0549, Oxoid) after incubation at $25^{\circ} \mathrm{C}$ for $5 \mathrm{~d}$. All experiments were carried out in triplicate, and the number of microorganisms was expressed as $\log _{10}$ of colony-forming units per gram $\left(\log _{10} \mathrm{cfu} / \mathrm{g}\right)$.

\section{Statistical Analysis}

All analytical determinations were performed at least in triplicate. Data obtained were analyzed using the statistical package SPSS for Windows XP V15.0 (2007; SPSS Inc., Chicago, IL). Significance of differences between treated samples was evaluated using Duncan's multiple range tests at a $5 \%$ level.

\section{RESULTS AND DISCUSSION}

\section{Acidity Parameters and $L A B$ Count in Basil-LAB Bioproducts}

Acidity parameters and LAB count in basil-LAB bioproducts are shown in Figure 1. Comparing the $\mathrm{pH}$ of samples before and after fermentation, the greatest decrease in $\mathrm{pH}$ was found in basil fermented with strain LUHS244 (25.4\% decrease), and the smallest in spontaneously fermented basil and basil fermented with strain LUHS29 (14.6 and 17.5\% decreases, respectively). Fermentation with LAB generally increases the organic acid mass fraction and antioxidant activity of the fermentable substrate (Bustos et al., 2017). The 
essential oil of basil is characterized by a high degree of antimicrobial activity but it does not inhibit the development of LAB in dairy starter cultures (Kostova et al., 2014). The LAB count in fermented basil ranged from $7.02 \pm 00.08$ to $7.47 \pm 0.06 \log _{10} \mathrm{cfu} / \mathrm{g}$ (fermented with LUHS135 and LUHS100, respectively), and in all cases was higher than the LAB count in nonfermented basil (3.02 $\left.\pm 0.07 \log _{10} \mathrm{cfu} / \mathrm{g}\right)$. However, acid formation in cheese samples with added basil essential oil can be lower but within acceptable values (Kostova et al., 2016). According to our results, basil-LAB bioproducts could be promising ingredients for cheese manufacturing because LAB were not inhibited and showed good growth and acidification rates in basil substrate.

\section{TPC Content and FRSA Before and After Immobilization}

The results for TPC content and DPPH FRSA of basil-LAB bioproducts before and after fermentation and immobilization are given in Figure $2 \mathrm{a}$ and $2 \mathrm{~b}$, respectively. Fermentation with selected LAB significantly increased $(P \leq 0.05)$ the TPC content in basil-LAB bioproducts (by $12.0 \%$ in basil fermented with LUHS140 and by $49.8 \%$ in basil fermented with LUHS135). However, we did not establish a significant effect of fermentation on the FRSA (by DPPH assay) of basil-LAB bioproducts. The immobilization process did not affect the TPC content in basil-LAB bioproducts, but a significantly lower FRSA was obtained for immobilized basil samples fermented with LUHS29,

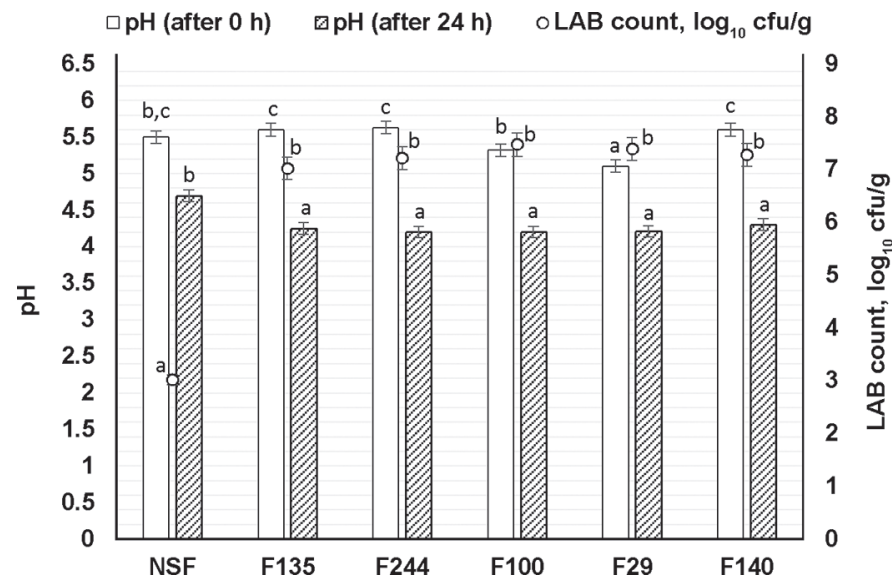

Figure 1. $\mathrm{pH}$ and lactic acid bacteria (LAB) count $\left(\log _{10} \mathrm{cfu} / \mathrm{g}\right)$ in basil-LAB bioproducts (data are expressed as mean $\pm \mathrm{SD} ; \mathrm{n}=3$ ). $\mathrm{NSF}=$ fermented spontaneously, $\mathrm{F}=$ fermented; $135=$ Lactobacillus plantarum LUHS135, $244=$ Lactobacillus paracasei LUHS244, 100 $=$ Pediococcus pentosaceus LUHS100, $29=$ Pediococcus acidilactici LUHS29, and $140=$ Lactobacillus brevis LUHS140.
LUHS244, and LUHS135 (by 12.4, 10.2, and 11.7\%, respectively; $P \leq 0.05$ ). The use of LAB or lactic acid fermentation is considered one of the most suitable technologies to exploit the functional potential of plant matrices and to enrich them with bioactive compounds (Pellati et al., 2004). Fermentation with selected LAB is largely used to enhance antimicrobial, antioxidant, and immune-modulatory features (Rizzello et al., 2013). Enhancement of antioxidant activity during fermentation is mainly ascribed to the release of bioactive compounds by LAB (Hur et al., 2014), and the addition of basil can increase the functional properties of dairy products (Mosiyani et al., 2017). Basil could be used in the food industry as a safer alternative to synthetic antioxidants (Stanojevic et al., 2017).

a)

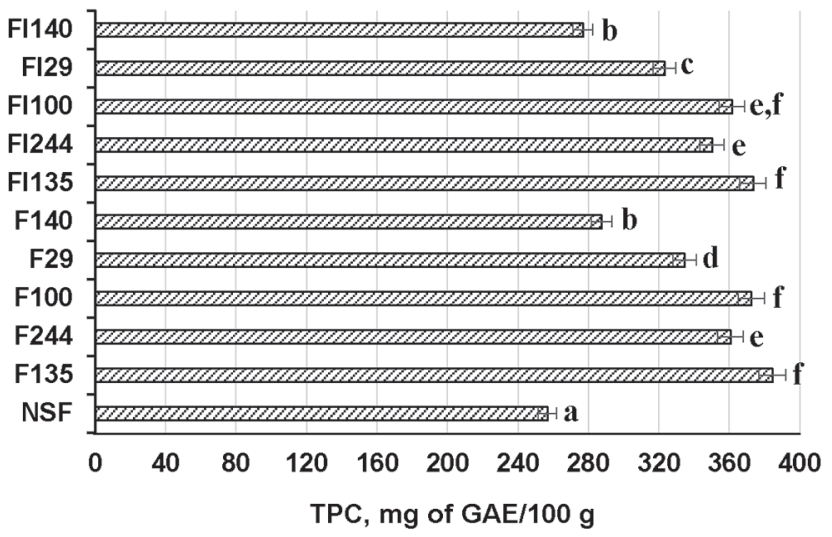

b)

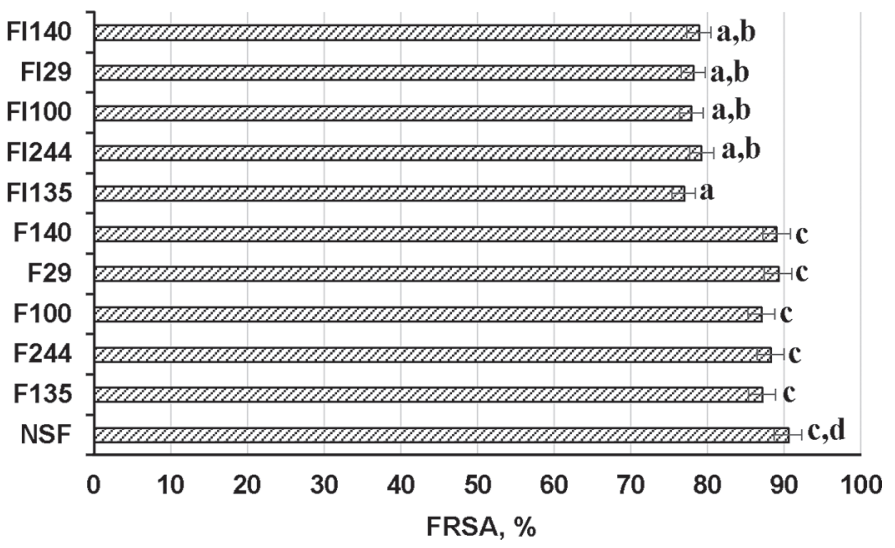

Figure 2. (a) Total phenolic compound (TPC) content (mg of gallic acid equivalents, GAE) and (b) 2,2-diphenyl-1-picrylhydrazyl (DPPH) free radical scavenging activity (FRSA) of basil-lactic acid bacteria (LAB) bioproducts (data are expressed as mean $\pm \mathrm{SD} ; \mathrm{n}=$ 3). $\mathrm{NSF}=$ fermented spontaneously, $\mathrm{F}=$ fermented, I = immobilized; $135=$ Lactobacillus plantarum LUHS135, $244=$ Lactobacillus paracasei LUHS244, $100=$ Pediococcus pentosaceus LUHS100, $29=$ Pediococcus acidilactici LUHS29, and $140=$ Lactobacillus brevis LUHS140. Mean values within a column with different letters (a-f) are significantly different $(P \leq 0.05)$. 


\section{Overall Acceptability and Color Characteristics Before and After Immobilization}

Overall acceptability and color characteristics of basil-LAB bioproducts before and after immobilization are shown in Table 1. Spontaneously fermented basil had the poorest overall acceptability (2 points) and was not selected for preparation of goat milk fresh cheese. Immobilization did not affect the overall acceptability of basil-LAB bioproducts; the most acceptable were those fermented with LUHS140 (5 points), followed by samples fermented with LUHS135, LUHS244, and LUHS29 (4 points), and samples fermented with LUHS100 (3 points).

Immobilization had a different influence on the lightness values $\left(\mathrm{L}^{*}\right)$ of the bioproducts because the different metabolites formed by the different LAB can influence color. In samples fermented with LUHS135, LUHS100, and LUHS140 after immobilization, $\mathrm{L}^{*}$ increased by $6.3,8.2$, and $7.4 \%$, respectively; in samples fermented with LUHS29, it decreased by $6.8 \%$, and in samples fermented with LUHS244, no significant changes in $\mathrm{L}^{*}$ were observed after immobilization. After immobilization, the redness $\left(\mathrm{a}^{*}\right)$ of basil-LAB bioproducts fermented with LUHS135, LUHS244, and LUHS100 increased significantly (by $20.6,16.8$, and $5.8 \%$, respectively; $P \leq 0.05)$. In contrast, a* values for samples fermented with LUHS29 and LUHS140 decreased after immobilization (by 19.5 and $18.6 \%$, respectively; $P \leq$ $0.05)$. Significantly different values of yellowness $\left(b^{*}\right)$ were detected in basil-LAB products after immobilization. In samples fermented with LUHS135, LUHS244, and LUHS140, we detected a significant increase in $b^{*}$ value; in contrast, a significant decrease in $b^{*}$ value was detected in samples fermented with LUHS100 and LUHS29 (by 10.7 and $6.8 \%$, respectively; $P \leq 0.05$ ).

In terms of functional properties, LAB can contribute to the release or production of compounds such as exopolysaccharides, vitamins, bioactive peptides, bioactive lipids, and enzymes in food; generally, fermented foods prepared with autochthonous LAB have better sensory acceptance (de Souza and Silva Dias, 2017). Our previous study showed that the chemical composition of volatile compounds had a less strong odor (lower concentration of essential oils) and was more acceptable to consumers, and some of the compounds are transformed by the appearance of new volatile compounds as a result of fermentation with different LAB (Juodeikiene et al., 2013). However, more research is needed on the transformation of basil volatile compounds during this process. Color is extremely important in food products because of its direct effect on appearance, and color is related to consumer acceptance (IFIC-FDA, 2010). Low $L^{*}$ values (darkening) are associated with

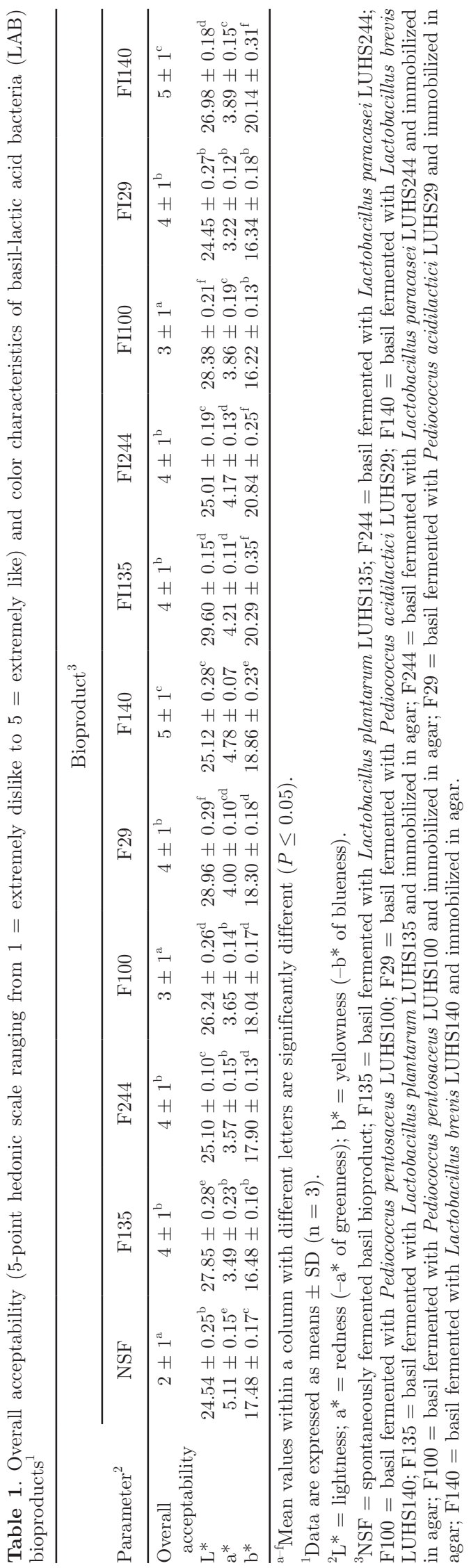


oxidation and enzymatic and microbiological degradation and are undesirable because they cause consumer rejection (Dattatreya and Rankin, 2006). Nonetheless, fermentation with selected LAB (because they produce different metabolites and have an influence on the different chemical composition of the fermentable substrate) has a different influence on the color characteristics of basil-LAB bioproducts because color can be influenced by metabolites formed (acids, peroxide, and so on).

\section{Effect of Basil-LAB Bioproducts on Acidity, Texture, Color, and Overall Acceptability of Goat Milk Fresh Cheese}

Results for acidity and texture parameters and for overall acceptability of goat milk fresh cheese are presented in Tables 2 and 3. Comparing all cheese samples, a significantly higher $\mathrm{pH}$ was found for cheese samples with nonimmobilized basil fermented with LUHS244 (5.82 \pm 0.06 ; Table 2$)$, and use of different LAB for preparation of basil-LAB bioproducts had a significant effect on cheese $\mathrm{pH}(P=0.04$; Table 3$)$. Immobilization and the interaction of immobilization and different LAB were not significant for cheese $\mathrm{pH}$ (Table 3). A significantly higher TTA $(P \leq 0.05)$ was obtained for cheese samples prepared with untreated basil and for samples prepared with basil fermented with LUHS135, LUHS244, LUHS100, and LUHS29 (higher by 33.3, $53.3,40.0,53.3,33.3$, and $66.7 \%$, respectively). In contrast to $\mathrm{pH}$, the TTA of cheese samples was significantly affected by the immobilization process $(P=0.002)$, and the interaction of the factors analyzed was significant $(P=0.004)$. The hardest texture was obtained for the cheese samples prepared with untreated basil and for samples prepared with basil fermented with LUHS244 and immobilized basil-LAB bioproducts $(0.5 \mathrm{~mJ})$. Use of different LAB for basil fermentation significantly affected cheese hardness $(P=0.001)$, and the interaction of different $\mathrm{LAB}$ and the immobilization process was significant $(P=0.001)$. Cheese-making relies on the fermentation of lactose by LAB to produce lactic acid, which lowers the $\mathrm{pH}$ and, in turn, assists coagulation, promotes syneresis, and contributes to cheese texture. Lactic acid bacteria also produce lipases and proteases, which are necessary for cheese texture formation (Medjoudj et al., 2018). A very weak positive correlation was found between cheese hardness and TTA ( $\mathrm{r}=$ 0.11). Overall acceptability of cheese was significantly influenced by the immobilization process $(P=0.011)$, and a moderate positive correlation was found between TTA and the overall acceptability of cheese samples $(\mathrm{r}=0.53)$. According to Costa et al. (2014), a correlation exists between the exposure sessions and an increase in acceptance of the exposure groups, and it

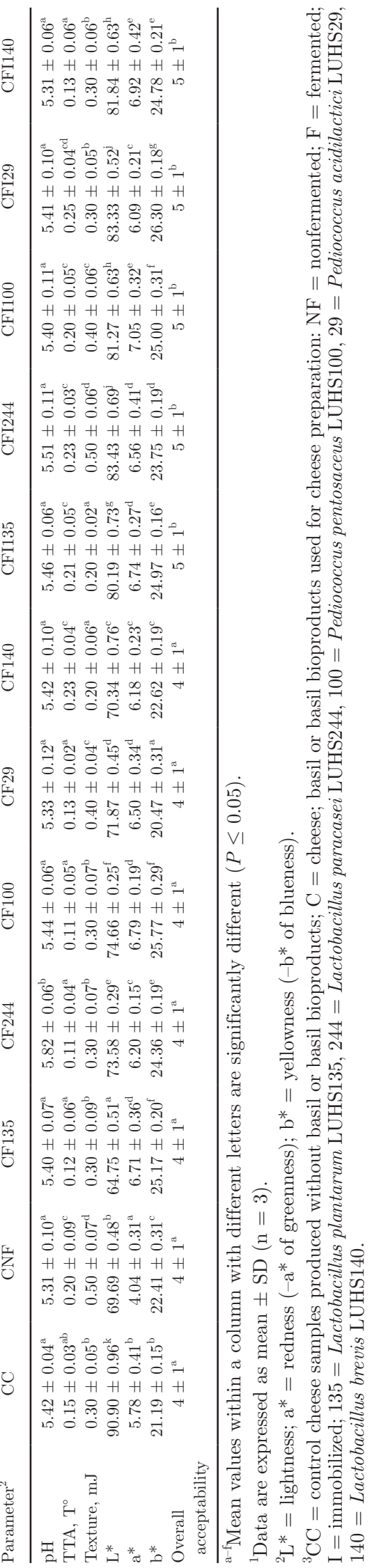

Journal of Dairy Science Vol. 101 No. 12, 2018 
could be that increasing exposure sessions could be a strategy to increase goat milk product acceptance. Finally, further studies, as well as projective methods, are recommended to establish the sensory profiling and consumer perception of cheese sensory properties (Fonseca et al., 2016; Esmerino et al., 2017; Oliveira et al., 2017). In all cases, basil-LAB bioproducts reduced the $\mathrm{L}^{*}$ values of cheese samples, but higher $\mathrm{L}^{*}$ values were established for cheese samples prepared with immobilized compared with immobilized basil-LAB bioproducts (Figure 3). Lightness values of 93.36 have been found for ricotta containing only goat milk (Borba et al., 2014), which is due to the presence of smaller fat globules compared with cow milk and conversion of $\beta$-carotene to vitamin A (Park et al., 2007). The factors analyzed in the current study (use of different LAB for basil fermentation and immobilization) and their interaction were significant for $\mathrm{L}^{*}$ values of cheese $(P=$ 0.0001). In all cases, basil-LAB bioproducts had higher $\mathrm{a}^{*}$ values than the control cheese and cheese prepared with untreated basil, and use of different LAB for basil fermentation significantly affected $a^{*}$ values of cheese $(P=0.0001)$. The lowest $\mathrm{b}^{*}$ value was observed for the control cheese samples $(21.19 \pm 0.15)$. In cheese samples prepared with fermented nonimmobilized basil-LAB bioproducts, $b^{*}$ values ranged from 20.47 \pm 0.31 to $25.77 \pm 0.29$ (cheese samples prepared with LUHS29 and LUHS100, respectively); for cheese samples prepared with fermented immobilized basil-LAB bioproducts, $b^{*}$ values ranged from $23.75 \pm 0.19$ to $26.30 \pm 0.18$ (cheese samples prepared with LUHS244 and LUHS29, respectively). All factors analyzed had a significant effect on the $\mathrm{b}^{*}$ values of cheese, and the interaction of factors analyzed was significant $(P=$ 0.0001). In all cases, better acceptability was obtained for cheese samples prepared with fermented and immobilized basil-LAB bioproducts (5 points). Control cheese samples and samples prepared with nonimmobilized basil-LAB bioproducts had poorer acceptability (4 points). Many factors influence the flavor, texture, and sensory qualities of goat milk cheeses. The flavor of cheese arises from a series of complex reactions involving microbial metabolism and enzymatic reactions, which include proteolysis of proteins, lipolysis of fats, and fermentation of carbohydrates (Moatsou and Park, 2017). Selected LAB improve nutritional quality, shelf life, and acceptability of soft white goat cheese (Mohammed et al., 2018), and basil enhances the volatile composition and acceptability of dairy products (Gurkan and Hayaloglu, 2017). According to our results, the use of immobilized basil-LAB bioproducts is a suitable method to improve the overall acceptability of fresh goat cheese; immobilization leads to the production of cheese with better acceptability compared with cheese produced with nonimmobilized basil.

\section{Microbiological Parameters of Curd Cheese During Storage}

Microbiological parameters of curd cheese during storage are shown in Table 4 . After $24 \mathrm{~h}$ of storage, no enterobacteria or mold/yeast were found in cheese

Table 3. The influence of different lactic acid bacteria (LAB) and immobilization process on fresh cheese parameters ${ }^{1}$

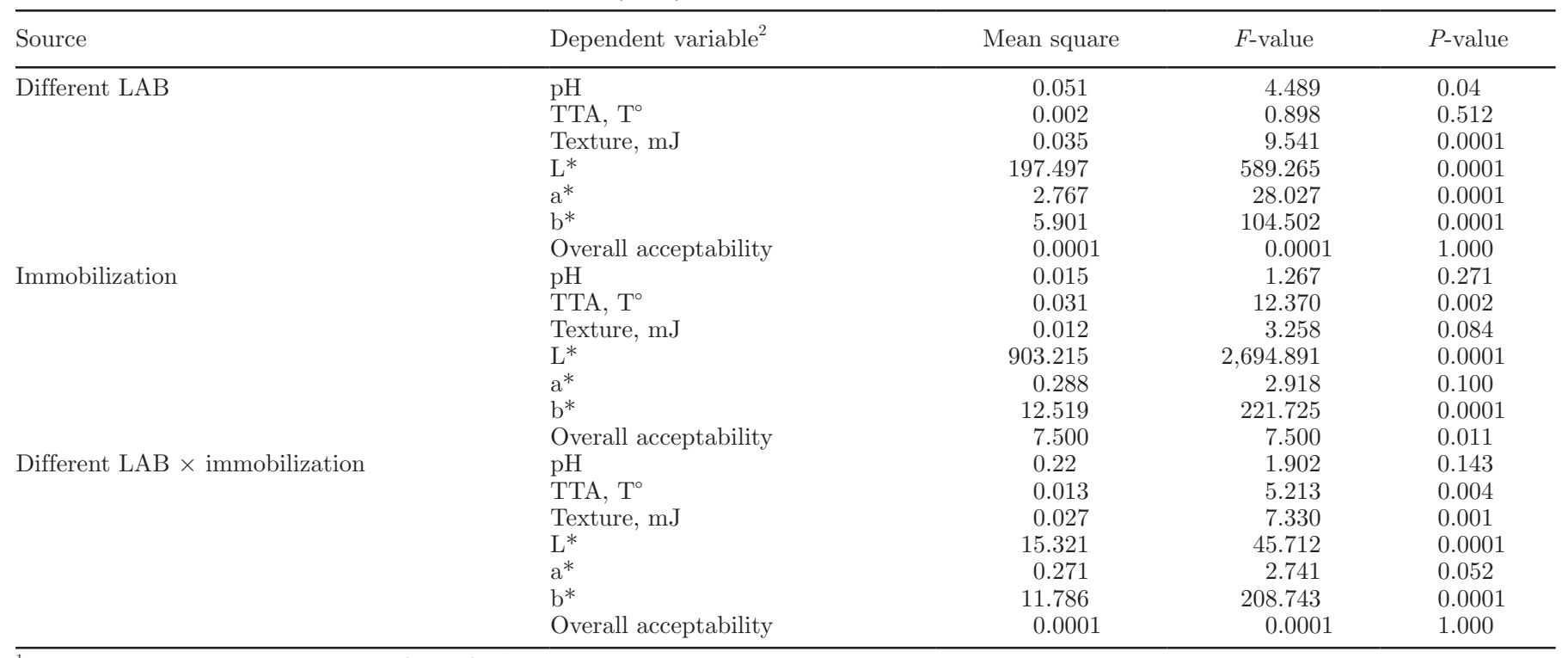

${ }^{1}$ Data are expressed as mean $\pm \mathrm{SD}(\mathrm{n}=3)$.

${ }^{2} \mathrm{TTA}=$ total titratable acidity; $\mathrm{L}^{*}=$ lightness; $\mathrm{a}^{*}=$ redness $\left(-\mathrm{a}^{*}\right.$ of greenness $) ; \mathrm{b}^{*}=$ yellowness $\left(-\mathrm{b}^{*}\right.$ of blueness $)$. 
samples, and the LAB count in cheese samples prepared with basil-LAB bioproducts was significantly higher than that of control cheese or cheese samples prepared with nonfermented basil. In all of the cheese samples prepared with basil-LAB bioproducts, the LAB count was $>6.0 \log _{10} \mathrm{cfu} / \mathrm{g}$, meeting the requirements for probiotic products. Comparing the LAB count in cheese samples prepared with nonimmobilized and immobilized basil-LAB bioproducts, a significantly higher $(P \leq 0.05)$ LAB count was found in cheese samples prepared with immobilized LUHS135, LUHS244, LUHS29, and LUHS140 basil-LAB bioproducts (by 12.3, 10.5, 7.9 , and $20.8 \%$, respectively). According to the results obtained, in most cases (except LUHS100 bioproducts), immobilization increased the stability of LAB in cheese, and a higher viable cell count was obtained in the end product. The average LAB count in fresh goat cheese prepared from nonpasteurized milk can reach $10^{8} \mathrm{cfu} / \mathrm{g}$ (Randazzo et al., 2002; Janštová et al., 2010). The relatively low level of contamination in the samples of natural fresh cheese can be explained by the fact that the cheese in the current study was made from pasteurized milk (Janštová et al., 2010). After 72 h of storage, enterobacteria were found in control cheese samples (prepared without basil or with untreated basil) and in cheese samples prepared with LUHS100 and LUHS29 basil-LAB bioproducts. A moderate negative correlation was obtained between LAB count and enterobacteria in cheese samples $(\mathrm{r}=-0.6365)$. Enterobacteriaceae counts in milk can reach $10^{2}$ to $10^{3} \mathrm{cfu} / \mathrm{g}$ under normal

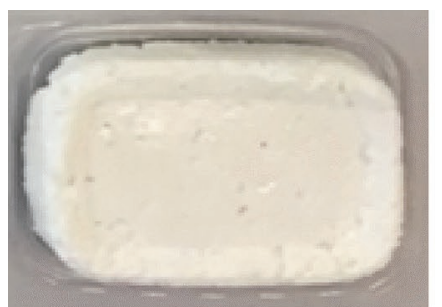

$\mathrm{CC}$

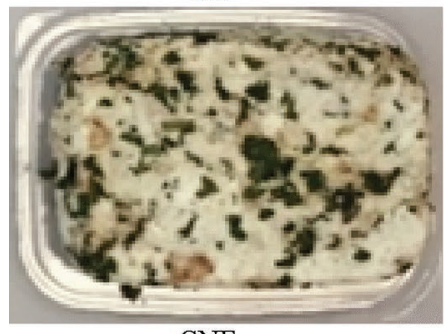

$\mathrm{CNF}$

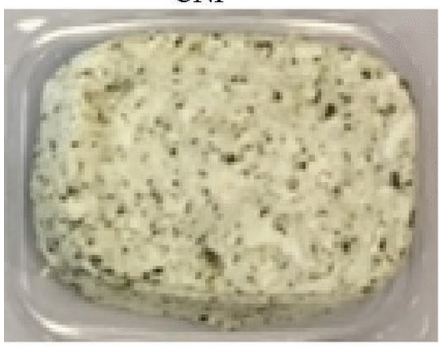

CFI100

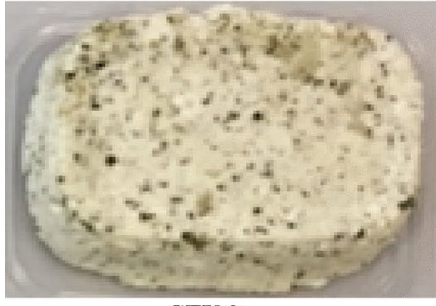

CFI29

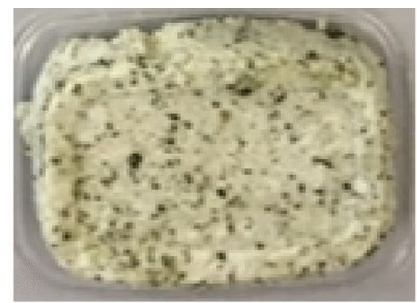

CFI135

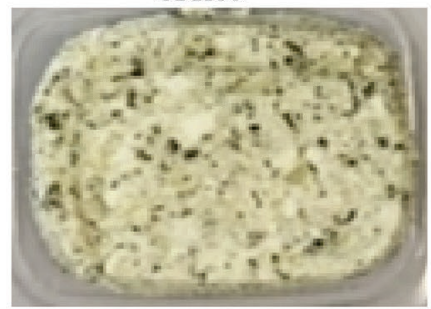

CFI244

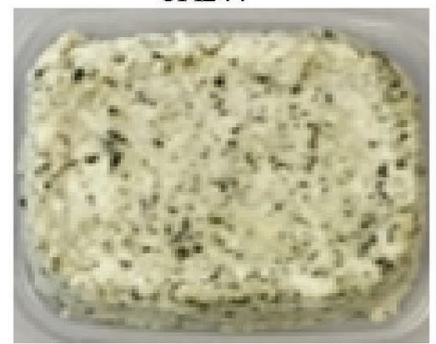

CFI140

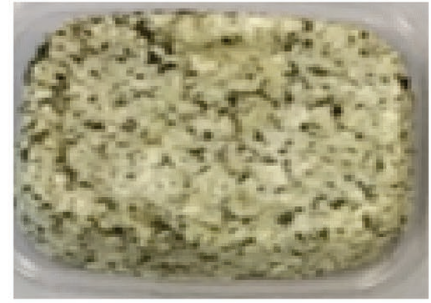

CF140

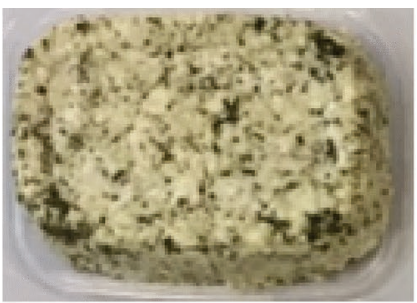

CF 100

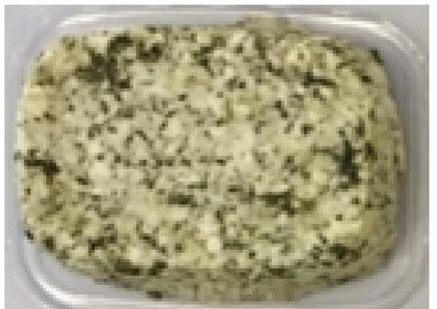

CF29

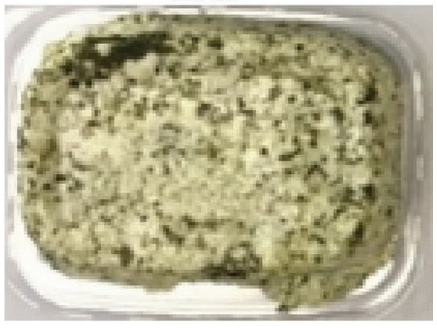

CF135

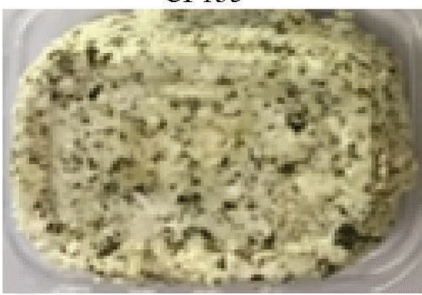

CF244

Figure 3. Images of the unripened goat milk curd cheese. $\mathrm{CC}=$ control cheese produced without basil bioproducts; $\mathrm{C}=$ cheese, $\mathrm{NF}=$ nonfermented, F = fermented, I = immobilized; $135=$ Lactobacillus plantarum LUHS135, $244=$ Lactobacillus paracasei LUHS244, $100=$ Pediococcus pentosaceus LUHS100, 29 = Pediococcus acidilactici LUHS29, and $140=$ Lactobacillus brevis LUHS140. Color version available online. 
conditions, and the counts may increase during the first week to reach $10^{6}$ to $10^{7} \mathrm{cfu} / \mathrm{g}$ in the inner portion of cheese; however, Enterobacteriaceae are sensitive to low $\mathrm{pH}$ values, and the use of LAB starters can reduce Enterobacteriaceae contamination by lowering the $\mathrm{pH}$ (Tornadijo et al., 2001). A weak positive correlation was found between LAB count and mold/yeast count in all cheese samples $(\mathrm{r}=0.3142)$. Although a high LAB count in cheese can reduce enterobacteria, yeasts are usually in a symbiotic relation with LAB; thus, increasing LAB has no influence on yeast count. After $120 \mathrm{~h}$ of storage, similar tendencies after $72 \mathrm{~h}$ were obtained for the enterobacteria; however, in cheese samples prepared with basil-LAB bioproducts, the enterobacteria count was lower by 35.9 and $36.9 \%$ in cheese samples prepared with nonimmobilized LUHS100 and LUHS29 bioproducts, respectively, and lower by $55.1 \%$ in cheese samples prepared with immobilized LUHSI100 and LUHSI29 bioproducts, respectively, than that in control cheese samples. In some cases, enterobacteria were not found (in cheese samples prepared with basil-LAB bioproducts fermented with LUHS135, LUHS244, and LUHS140). After $120 \mathrm{~h}$ of storage, strong and moderate negative correlations were found between LAB count and enterobacteria count and between LAB count and yeast/mold count $(\mathrm{r}=-0.7939$ and $\mathrm{r}=-0.4495$, respectively). Goat milk is most commonly used for the production of fresh unripened cheese, and bacterial spoilage may occur in fresh cheeses having a sufficiently high pH (Janštová et al., 2010). Basil essential oils are promising antimicrobial and antifungal agents for food formulations; their antibacterial activity is attributed to their high linalool and estragole content, but the antimicrobial spectrum is restricted to specific bacteria (Staphylococcus spp., Enterococcus spp., Escherichia coli, Pseudomonas aeruginosa, Acinetobacter baumannii, Aeromonas hydrophila, Bacillus cereus, Bacillus subtilis, Enterobacter spp., Listeria spp., Proteus spp., Salmonella spp., Serratia marcescens, and Yersinia enterocolitica) and fungi (Candida spp., Rhodotorula spp., and Saccharomyces cerevisiae) (Sakkas and Papadopoulou, 2017). Basil extracts are recommended as natural food preservatives because of their role in the control of food-borne pathogens as biological food contaminants, in addition to their antioxidant and anti-inflammatory activities (Hamad et al., 2017). According to our results, immobilization increases LAB viability in fresh cheese, and basil-LAB bioproducts reduce the contamination of cheese during storage.

\section{CONCLUSIONS}

Fermented basil could be a promising multifunctional ingredient for cheese manufacturing because its inclu- 
sion resulted in cheese with a lower $\mathrm{pH}$, a higher $\mathrm{LAB}$ count, a higher content of total phenolic compounds, and a lower enterobacteria count (in cheese samples prepared with basil-LAB bioproducts fermented with LUHS135, LUHS244, and LUHS140). Immobilization of the fermented basil led to higher sensory acceptability of cheeses. We confirmed the hypothesis of this study: immobilization increased LAB viability in fresh goat milk cheese, which led to a reduction in contamination during storage and an increase in overall acceptability compared with use of nonimmobilized basil-LAB bioproducts. Basil-LAB bioproducts fermented with LUHS135, LUHS244, and LUHS140 strains are recommended for the preparation of extended-shelf-life goat milk fresh cheese that is acceptable to consumers.

\section{ACKNOWLEDGMENTS}

The authors acknowledge the Lithuanian University of Health Sciences for the partial financial support of this study (Rector order 09012017 No. V-31).

\section{REFERENCES}

Avetisyan, A., A. Markosian, M. Petrosyan, N. Sahakyan, A. Babayan, S. Aloyan, and A. Trchounian. 2017. Chemical composition and some biological activities of the essential oils from basil Ocimum different cultivars. BMC Complement. Altern. Med. 17:60-67.

Borba, K. K. S., F. A. Silva, M. S. Madruga, R. C. R. Queiroga, E. L. Souza, and M. Magnani. 2014. The effect of storage on nutritional, textural and sensory characteristics of creamy ricotta made from whey as well as cow's milk and goat's milk. Int. J. Food Sci. Technol. 49:1279-1286.

Bulajic, S., T. Ledina, J. Djordjevic, M. Boskovic, V. Matovic, R. Markovic, and M. Z. Baltic. 2017. Biopreservation of traditional raw milk cheeses with an emphasis on Serbian artisanal cheeses and their historical production. Meat Technol. 58:52-61.

Bustos, A. Y., C. L. Gerez, L. G. M. Mohtar, V. I. P. Zanini, M. A. Nazareno, M. P. Taranto, and L. B. Iturriaga. 2017. Lactic acid fermentation improved textural behaviour, phenolic compounds and antioxidant activity of chia (Salvia hispanica L.) dough. Food Technol. Biotechnol. 55:381.

Costa, M. P., C. F. Balthazar, R. M. Franco, E. T. Mársico, A. G. Cruz, and C. A. Conte Junior. 2014. Changes on expected taste perception of probiotic and conventional yogurts made from goat milk after rapidly repeated exposure. J. Dairy Sci. 97:2610-2618.

Dattatreya, A., and S. A. Rankin. 2006. Moderately acidic $\mathrm{pH}$ potentiates browning of sweet whey powder. Int. Dairy J. 16:822-828.

de Souza, J. V., and F. Silva Dias. 2017. Protective, technological, and functional properties of select autochthonous lactic acid bacteria from goat dairy products. Curr. Opin. Food Sci. 13:1-9.

Esmerino, E. A., J. P. Ferraz, E. R. T. Filho, L. P. F. Pinto, M. Q. Freitas, A. G. Cruz, and H. M. A. Bolini. 2017. Consumers' perceptions toward 3 different fermented dairy products: Insights from focus groups, word association, and projective mapping. J. Dairy Sci. 100:8849-8860.

Fonseca, F. G. A., E. A. Esmerino, E. R. T. Filho, J. P. Ferraz, A. G. da Cruz, and H. M. A. Bolini. 2016. Novel and successful free comments method for sensory characterization of chocolate ice cream: A comparative study between pivot profile and comment analysis. J. Dairy Sci. 99:3408-3420.

Gaze, L. V., B. R. Oliveira, L. L. Ferrao, D. Granato, R. N. Cavalcanti, C. A. Conte Júnior, A. G. Cruz, and M. Q. Freitas. 2015.
Preference mapping of dulce de leche commercialized in Brazilian markets. J. Dairy Sci. 98:1443-1454.

Gouvea, F. D. S., A. Rosenthal, and E. H. D. R. Ferreira. 2017. Plant extract and essential oils added as antimicrobials to cheeses: A review. Cienc. Rural 47:1-9.

Gurkan, H., and A. A. Hayaloglu. 2017. Volatiles and sensory characteristics of yogurt manufactured by incorporating basil (Ocimum basilicum L.). Int. J. Food Prop. 20:S779-S789.

Hamad, G. M., A. M. Darwish, M. M. Abu-Serie, and S. A. El Sohaimy. 2017. Antimicrobial, antioxidant and anti-inflammatory characteristics of combination (Cassia fistula and Ocimum basilicum) extract as natural preservative to control \& prevent food contamination. J. Food Nutr. Res. 5:771-780.

Huang, H. C., Y. C. Ho, J. M. Lim, T. Y. Chang, C. L. Ho, and T. M. Chang. 2015. Investigation of the anti-melanogenic and antioxidant characteristics of Eucalyptus camaldulensis flower essential oil and determination of its chemical composition. Int. J. Mol. Sci. 16:10470-10490.

Hur, S. J., S. Y. Lee, Y. C. Kim, I. Choi, and G. B. Kim. 2014. Effect of fermentation on the antioxidant activity in plant-based foods. Food Chem. 160:346-356.

IFIC-FDA. 2010. Food Ingredients \& Colors. International Food Information Council Foundation (IFIC) and US Food and Drug Administration (FDA), Washington, DC.

ISO. 1998. ISO 15214: Microbiology of food and animal feeding stuffsHorizontal method for the enumeration of mesophilic lactic acid bacteria-Colony-count technique at $30^{\circ} \mathrm{C}$. International Organization for Standardization (ISO), Geneva, Switzerland.

ISO. 2008. ISO 5492: Sensory analysis-Vocabulary. International Organization for Standardization (ISO), Geneva, Switzerland.

ISO. 2012. ISO 8586: Sensory analysis-General guidelines for the selection, training and monitoring of selected assessors and expert sensory assessors. International Organization for Standardization (ISO), Geneva, Switzerland.

ISO. 2017. ISO 6658: Sensory analysis-Methodology: General guidance. International Organization for Standardization (ISO), Geneva, Switzerland.

Jalilzadeh, A., Y. Tunçtürk, and J. Hesari. 2015. Extension shelf life of cheese: A review. Int. J. Dairy Sci. 10:44-60.

Janiaski, D. R., T. C. Pimentel, A. G. Cruz, and S. H. Prudencio. 2016. Strawberry-flavored yogurts and whey beverages: What is the sensory profile of the ideal product? J. Dairy Sci. 99:5273-5283.

Janštová, B., M. Dračková, S. Cupáková, H. Přidalová, M. Pospíšilová, R. Karpíšková, and L. Vorlová. 2010. Safety and quality of farm fresh goat's cheese in the Czech Republic. Czech J. Food Sci. $28: 1-8$.

Juodeikiene, G., D. Cizeikiene, V. Ceskeviciute, D. Vidmantiene, L. Basinskiene, I. Akuneca, M. Stankevicius, A. Maruska, E. Bartkiene, O. Ragazinskiene, and A. Petrauskas. 2013. Wheat bread with fermented Silybum marianum seeds. Food Technol. Biotechnol. 51:528-538.

Khorshidian, N., M. Yousefi, E. Khanniri, and A. M. Mortazavian. 2017. Potential application of essential oils as antimicrobial preservatives in cheese. Innov. Food Sci. Emerg. Technol. 45:62-72.

Kilcast, D., and P. Subramaniam, ed. 2011. Food and Beverage Stability and Shelf Life. 1st ed. Woodhead Publishing Series in Food Science, Technology and Nutrition. Woodhead Publishing, Cambridge, UK.

Klimankova, E., K. Holadova, J. Hajslova, T. Cajka, J. Poustka, and M. Koudela. 2008. Aroma profile of five basil (Ocimum basilicum L.) cultivars grown under conventional and organic conditions. Food Chem. 107:464-472.

Kostova, I., S. Damyanova, N. Ivanova, A. Stoyanova, M. Ivanova, and R. Vlaseva. 2016. Use of essential oils in dairy products. Essential oil of basil (Ocimum basilicum L.). Indian J. Appl. Res. 6:54-56.

Kostova, I., D. Dimitrov, M. Ivanova, R. Vlaseva, S. Damyanova, N. Ivanova, and A. Stoyanova. 2014. Studying the possibilities of using of essential oils in dairy products. 3. Basil (Ocimum basilicum). J. Food Pack. Sci. Tech. Technol. 5:17-21. 
Liu, K., Q. Cheng, Y. Liu, X. Zhou, and X. Wang. 2012. Isolation and biological activities of decanal, linalool, valencene, and octanal from sweet orange oil. J. Food Sci. 77:C1156-1161.

Medjoudj, H., L. Aouar, M. N. Zidoune, and A. A. Hayaloglu. 2018. Proteolysis, microbiology, volatiles and sensory evaluation of Algerian traditional cheese Bouhezza made using goat's raw milk. Int. J. Food Prop. 20:1-20.

Moatsou, G., and Y. W. Park. 2017. Goat milk products: Types of products, manufacturing technology, chemical composition, and marketing. Pages 84-149 in Handbook of Milk of Non-Bovine Mammals. 2nd ed. Y. W. Park, G. F. W. Haenlein, W. L. Wendorff, ed. Wiley-Blackwell Publishers, Chichester, UK.

Mohammed, S. S. D., J. R. Wartu, A. H. Aminu, A. A. D. David, and B. J. Musa. 2018. Biol.-preservation of Nigerian soft-white cheese in submerged consortium of bacteriocinogenic lactic acid bacteria culture. Afr. J. Biotechnol. 17:118-125.

Mosiyani, Z. G., R. Pourahmad, and M. R. Eshaghi. 2017. Investigating the effect of aqueous extracts of basil and savory on antioxidant activity, microbial and sensory properties of probiotic yogurt. Acta Sci. Pol. Technol. Aliment. 16:311-320.

Mozuriene, E., E. Bartkiene, G. Juodeikiene, D. Zadeike, L. Basinskiene, A. Maruska, M. Stankevicius, O. Ragazinskiene, J. Damasius, and D. Cizeikiene. 2016. The effect of savoury plants, fermented with lactic acid bacteria, on the microbiological contamination, quality, and acceptability of unripened curd cheese. Lebensm. Wiss. Technol. 69:161-168.

Oliveira, E. W., E. A. Esmerino, B. Thomas Carr, L. P. F. Pinto, H. L. A. Silva, T. C. Pimentel, H. M. A. Bolini, A. G. Cruz, and M. Q. Freitas. 2017. Reformulating Minas Frescal cheese using consumers' perceptions: Insights from intensity scales and check-all-thatapply questionnaires. J. Dairy Sci. 100:6111-6124.

Park, Y. W., M. Juarez, M. Ramos, and G. F. W. Haenlein. 2007. Physicochemical characteristics of goat and sheep milk. Small Rumin. Res. 68:88-113.

Pellati, F., S. Benvenuti, L. Magro, M. Melegari, and F. Soragni. 2004. Analysis of phenolic compounds and radical scavenging activity of Echinacea spp. J. Pharm. Biomed. Anal. 35:289-301.

Randazzo, C. L., S. Torriani, A. D. Akkermans, W. M. de Vos, and E. E. Vaughan. 2002. Diversity, dynamics and activity of bacterial communities during production of an artisanal Sicilian cheese as evaluated by $16 \mathrm{r}$ RNA analysis. Appl. Environ. Microbiol. 68:1882-1892.
Rizzello, C. G., R. Coda, D. Sánchez-Macías, D. Pinto, B. Marzani, P. Filanino, G. Giuliani, V. M. Paradiso, R. Di Cagno, and M. Gobbetti. 2013. Lactic acid fermentation as a tool to enhance the functional features of Echinacea spp. Microb. Cell Fact. 12:44.

Sakkas, H., and C. Papadopoulou. 2017. Antimicrobial activity of basil, oregano, and thyme essential oils. J. Microbiol. Biotechnol. $27: 429-438$.

Soković, M., P. D. Marin, D. L. Brkić, and L. J. L. D. van Griensven 2007. Chemical composition and antibacterial activity of essential oils of ten aromatic plants against human pathogenic bacteria. Glob. Sci. Res. J. 1:220-226.

Stanojevic, L. P., Z. R. Marjanovic-Balaban, V. D. Kalaba, J. S. Stanojevic, D. J. Cvetkovic, and M. D. Cakic. 2017. Chemical composition, antioxidant and antimicrobial activity of basil (Ocimum basilicum L.) essential oil. J. Essent. Oil Bearing Plants 20:1557-1569.

Tamang, J. P., K. Watanabe, and W. H. Holzapfel. 2016. Review: Diversity of microorganisms in global fermented foods and beverages. Front. Microbiol. 7:377. https://doi.org/10.3389/fmicb.2016 .00377 .

Tornadijo, M. E., M. C. Garcia, J. M. Fresno, and J. Carballo. 2001 Study of Enterobacteriaceae during the manufacture and ripening of San Simon cheese. Food Microbiol. 2001:499-509.

Torres, F. R., E. A. Esmerino, B. T. Carr, L. L. Ferrão, D. Granato, T. C. Pimentel, H. M. A. Bolini, M. Q. Freitas, and A. G. Cruz. 2017. Rapid consumer-based sensory characterization of requeijão cremoso, a spreadable processed cheese: Performance of new statistical approaches to evaluate check-all-that-apply data. J. Dairy Sci. 100:6100-6110.

Vaher, M., K. Matso, T. Levandi, K. Helmja, and M. Kaljurand. 2010. Phenolic compounds and the antioxidant activity of the bran, flour and whole grain of different wheat varieties. Procedia Chem. 2:76-82.

Yangilar, F. 2013. As a potentially functional food: Goats' milk and products. J. Food Nutr. Res. 1:68-81.

Zabka, M., R. Pavela, and E. Prokinova. 2014. Antifungal activity and chemical composition of twenty essential oils against significant indoor and outdoor toxigenic and aeroallergenic fungi. Chemosphere 112:443-448.

Zhu, K. X., C. X. Lian, X. N. Guo, W. Peng, and H. M. Zhou. 2011. Antioxidant activities and total phenolic contents of various extracts from defatted wheat germ. Food Chem. 126:1122-1126. 